\title{
Bimolecular Reaction Dynamics in the Phenyl - Silane System: Exploring the Prototype of a Radical Substitution Mechanism
}

\author{
Michael Lucas ${ }^{1}$, Aaron M. Thomas ${ }^{1}$, Tao Yang ${ }^{1}$, Ralf I. Kaiser ${ }^{1 *}$, Alexander M. Mebel², \\ Diptarka Hait ${ }^{3}$, Martin Head-Gordon ${ }^{3,4 *}$
}

${ }^{1}$ Department of Chemistry, University of Hawai'i at Manoa, Honolulu, HI 96822

${ }^{2}$ Department of Chemistry and Biochemistry, Florida International University, Miami, FL 33199

${ }^{3}$ Kenneth S. Pitzer Center for Theoretical Chemistry, Department of Chemistry, University of California, Berkeley, CA 94720

${ }^{4}$ Chemical Sciences Division, Lawrence Berkeley National Laboratory, Berkeley, CA 94720

*Email: ralfk@hawaii.edu

*Email: $\underline{\text { mhg@cchem.berkeley.edu }}$ 


\begin{abstract}
We present a combined experimental and theoretical investigation of the bimolecular gas phase reaction of the phenyl radical $\left(\mathrm{C}_{6} \mathrm{H}_{5}\right)$ with silane $\left(\mathrm{SiH}_{4}\right)$ under single collision conditions to investigate the chemical dynamics of forming phenylsilane $\left(\mathrm{C}_{6} \mathrm{H}_{5} \mathrm{SiH}_{3}\right)$ via a bimolecular radical substitution mechanism at a tetra-coordinated silicon atom. Verified by electronic structure and quasiclassical trajectory calculations, the replacement of a single carbon atom in methane by silicon lowers the barrier to substitution thus defying conventional wisdom that tetra-coordinated hydrides undergo preferentially hydrogen abstraction. This reaction mechanism provides fundamental insights into the hitherto unexplored gas phase chemical dynamics of radical substitution reactions of mononuclear main group hydrides under single collision conditions and highlights the distinct reactivity of silicon compared to its isovalent carbon. This mechanism might be also involved in the synthesis of cyanosilane $\left(\mathrm{SiH}_{3} \mathrm{CN}\right)$ and methylsilane $\left(\mathrm{CH}_{3} \mathrm{SiH}_{3}\right)$ probed in the circumstellar envelope of the carbon star IRC+10216.
\end{abstract}


For the last century, substitution reaction mechanisms such as nucleophilic $\left(\mathrm{S}_{\mathrm{N}}\right)$, electrophilic $\left(\mathrm{S}_{\mathrm{E}}\right)$, and radical substitutions $\left(\mathrm{S}_{\mathrm{R}}\right)$ at aromatic moieties have been among the most fundamental classes of chemical reactions exploited in organic chemistry. ${ }^{1-4}$ These reactions represent crucial paradigms for methods that efficiently increase the structural complexity of (polycyclic) aromatic molecules involving intermediates with tetra-coordinated ( $\mathrm{sp}^{3}$ hybridized) carbon atoms. Whereas the dynamics of these aromatic substitution reactions have been explored at the molecular level in great detail, ${ }^{4-6}$ an understanding of aliphatic substitution reactions at tetracoordinated atoms at the most fundamental, molecular level has been beginning to emerge only recently. In nucleophilic aliphatic substitution reactions, an electron-rich nucleophile $\left(\mathrm{Nu}^{-}\right)$bonds with or attacks the positive $\left(S_{N} 1\right)$ or the partially positive charge of a carbon atom $\left(S_{N} 2\right)$ to eventually replace a leaving group $\mathrm{X}^{-4-5}$ In electrophilic substitutions involving aliphatic molecules such as the $\mathrm{S}_{\mathrm{E}} 1$ and $\mathrm{S}_{\mathrm{E}} 2$ mechanisms, an electrophile $\mathrm{E}^{+}$ultimately displaces a functional group $E$ '. In $S_{E} 1$, the reactant first ionizes into a carbanion along with a positively charged group, with the carbanion rapidly recombining with the electrophile $\left(\mathrm{E}^{+}\right)$; following a $\mathrm{S}_{\mathrm{E}} 2$ route, only one transition state exists, in which the old bond breaks and the new bond forms simultaneously. 4,6

Although these substitution reactions play a pivotal role in chemical synthesis and in physical organic chemistry - especially for interchanging functional groups and carbon-carbon bond coupling - a radical-type substitution reaction at tetra-coordinated carbon atoms in aliphatic molecules in the gas phase such as the reaction of atomic deuterium $(\mathrm{D} \cdot)$ with methane $\left(\mathrm{CH}_{4}\right)$, [1a], has so far received little attention. ${ }^{7}$ Here, both the hydrogen abstraction channel [1b] and the deuteriumhydrogen exchange [1a] are close to thermoneutral, but have significantly different barriers of 63 $\mathrm{kJ} \mathrm{mol}^{-1}$ versus $159 \mathrm{~kJ} \mathrm{~mol}^{-1}$, respectively. ${ }^{7}$ Therefore, in radical reactions involving molecules with $\mathrm{sp}^{3}$ hybridized carbon atoms such as in methane, the hydrogen abstraction pathway is clearly preferred ${ }^{8-9}$.

$$
\begin{aligned}
& \text { D• }+\mathrm{CH}_{4} \rightarrow \mathrm{CDH}_{3}+\mathrm{H} \cdot \\
& \text { D. }+\mathrm{CH}_{4} \rightarrow \mathrm{DH}+\mathrm{CH}_{3} \cdot
\end{aligned}
$$

In this Letter, we reveal, via a combined crossed molecular beam and computational investigation, that the replacement of a single carbon atom in methane by an isovalent silicon atom and the reaction of silane $\left(\mathrm{SiH}_{4}\right)$ with the phenyl radical $\left(\mathrm{C}_{6} \mathrm{H}_{5}{ }^{\circ}\right)$ under single collision conditions in 
the gas phase open up an unusual radical substitution pathway at a tetra-coordinated silicon atom (reaction [2a]), which is viable even in the presence of the classical hydrogen abstraction (reaction [2b]). This reaction forms phenylsilane $\left(\mathrm{C}_{6} \mathrm{H}_{5} \mathrm{SiH}_{3}\right)$ plus atomic hydrogen $(\mathrm{H} \cdot)$ via a trigonal bipyramidal transition state involving a simultaneous silicon-carbon bond formation and a silicon-hydrogen bond rupture. Compared to the isovalent methane $\left(\mathrm{CH}_{4}\right)$ - phenyl radical $\left(\mathrm{C}_{6} \mathrm{H}_{5} \cdot\right)$ system (reactions [3a/3b]), the barrier to substitution is lowered by $131 \mathrm{~kJ} \mathrm{~mol}^{-1}$ (reaction [2a]) thus making the substitution pathway in the silane - phenyl system [2a] more competitive with the hydrogen abstraction channel [2b] than in methane - phenyl reactive collisions [3a] versus [3b]. These results provide fundamental insights into the hitherto poorly unexplored chemistry and chemical dynamics of bimolecular gas phase radical substitution reactions at tetracoordinated main group atoms and highlight the unique differences in the reactivity of silicon compared to carbon. These differences can lead to unconventional silicon-carbon bond couplings via radical substitution reactions with potentially fundamental applications in synthetic and interstellar chemistry.

$$
\begin{aligned}
\mathrm{C}_{6} \mathrm{H}_{5} \cdot+\mathrm{SiH}_{4} & \rightarrow \mathrm{C}_{6} \mathrm{H}_{5} \mathrm{SiH}_{3}+\mathrm{H} \cdot \\
\mathrm{C}_{6} \mathrm{H}_{5} \cdot+\mathrm{SiH}_{4} & \rightarrow \mathrm{C}_{6} \mathrm{H}_{6}+\mathrm{SiH}_{3} \cdot \\
\mathrm{C}_{6} \mathrm{H}_{5} \cdot+\mathrm{CH}_{4} & \rightarrow \mathrm{C}_{6} \mathrm{H}_{5} \mathrm{CH}_{3}+\mathrm{H} \cdot \\
\mathrm{C}_{6} \mathrm{H}_{5} \cdot+\mathrm{CH}_{4} & \rightarrow \mathrm{C}_{6} \mathrm{H}_{6}+\mathrm{CH}_{3} \cdot
\end{aligned}
$$

The experiments were conducted under single-collision conditions at a collision energy of $38.0 \pm 1.3 \mathrm{~kJ} \mathrm{~mol}^{-1}$ exploiting a crossed molecular beam apparatus. The $193 \mathrm{~nm}$ output of an excimer laser was focused downstream of a pulsed valve and intersected a beam of heliumseeded chlorobenzene $\left(\mathrm{C}_{6} \mathrm{H}_{5} \mathrm{Cl}\right)$. The supersonic beam of phenyl radicals $\left(\mathrm{C}_{6} \mathrm{H}_{5} ; 77 \mathrm{amu}\right)$ generated in this photodissociation process crossed a beam of silane $\left(\mathrm{SiH}_{4} ; 32 \mathrm{amu}\right)$ molecules perpendicularly in the interaction region of the scattering chamber. Time-of-flight spectra (TOF) and the product angular distribution of the reactively scattered products were recorded in the scattering plane at mass to charge ratios $(\mathrm{m} / \mathrm{z})$ from $\mathrm{m} / \mathrm{z}=109\left(\mathrm{C}_{6} \mathrm{H}_{9} \mathrm{Si}^{+}\right)$to $105\left(\mathrm{C}_{6} \mathrm{H}_{5} \mathrm{Si}^{+}\right)$ utilizing a triply differentially pumped quadrupole mass spectrometer (QMS) operated at 10-11 Torr with an electron impact ionizer (80 eV; $2 \mathrm{~mA})$. 
Accounting for the natural isotope abundances of silicon of ${ }^{30} \mathrm{Si}(3.1 \%),{ }^{29} \mathrm{Si}(4.67 \%)$, and ${ }^{28} \mathrm{Si}(92.23 \%)$ and considering that after scaling, the TOF spectra recorded from $\mathrm{m} / \mathrm{z}=108$ to 105 depict identical patterns, we conclude that signal from $\mathrm{m} / \mathrm{z}=107$ to 105 originates from dissociative ionization of the $\mathrm{C}_{6} \mathrm{H}_{8}{ }^{28} \mathrm{Si}$ parent (108 amu; hereafter: $\mathrm{C}_{6} \mathrm{H}_{8} \mathrm{Si}$ ) formed as the heavy product in the reaction of the phenyl radical $\left(\mathrm{C}_{6} \mathrm{H}_{5}\right)$ with silane $\left(\mathrm{SiH}_{4}\right)$; silicon isotopes along with isotopically substituted fragments can also contribute to $\mathrm{m} / \mathrm{z}=107\left(\mathrm{C}_{6} \mathrm{H}_{6}{ }^{29} \mathrm{Si}^{+}, \mathrm{C}_{6} \mathrm{H}_{5}{ }^{30} \mathrm{Si}^{+}\right)$, $m / z=106\left(\mathrm{C}_{6} \mathrm{H}_{5}{ }^{29} \mathrm{Si}^{+}, \mathrm{C}_{6} \mathrm{H}_{4}{ }^{30} \mathrm{Si}^{+}\right)$, and $105\left(\mathrm{C}_{6} \mathrm{H}_{4}{ }^{29} \mathrm{Si}^{+}, \mathrm{C}_{6} \mathrm{H}_{3}{ }^{30} \mathrm{Si}^{+}\right)$. No evidence for the adduct at $\mathrm{m} / \mathrm{z}=109\left(\mathrm{C}_{6} \mathrm{H}_{9}{ }^{28} \mathrm{Si}^{+}\right)$was found. Eventually, reactive scattering signal was monitored at $\mathrm{m} / \mathrm{z}=$ 105 as it provided the best signal-to-noise ratio with the TOF spectra and laboratory angular distribution (Fig. 1). The laboratory angular distribution is very narrow spreading over only about $10^{\circ}$. Despite this narrow range, a preferentially backward-scattered laboratory angular distribution was derived. These raw data alone suggest that a molecule with the molecular formula $\mathrm{C}_{6} \mathrm{H}_{8} \mathrm{Si}(108 \mathrm{amu})$ along with atomic hydrogen $(\mathrm{H} \cdot ; 1 \mathrm{amu})$ is formed in the reaction of the phenyl radical $\left(\mathrm{C}_{6} \mathrm{H}_{5} \cdot\right)$ with silane $\left(\mathrm{SiH}_{4}\right)$.

The crossed molecular beam studies combined with our electronic structure calculations reveal further insights into the chemical dynamics of the reaction and provide crucial information on the $\mathrm{C}_{6} \mathrm{H}_{8} \mathrm{Si}$ isomer formed. Here, information on the reaction dynamics were obtained via fitting of the laboratory data with a forward-convolution routine eventually yielding the angular flux distribution, $T(\theta)$, and the translational-energy flux distribution, $P\left(E_{T}\right)$, in the center-of-mass reference frame (Fig. 2). The product flux contour map, $I(\theta, \mathrm{u})=P(\mathrm{u}) \times T(\theta)$, represents an image of the reaction and reports the intensity of the reactively scattered products $(I)$ as a function of the center-of-mass scattering angle $(\theta)$ and product velocity $(\mathrm{u})$. The laboratory data could be fit with a single channel leading from phenyl $\left(\mathrm{C}_{6} \mathrm{H}_{5} ; 77 \mathrm{amu}\right)$ plus silane $\left(\mathrm{SiH}_{4} ; 32 \mathrm{amu}\right)$ reactants to the formation of $\mathrm{C}_{6} \mathrm{H}_{8} \mathrm{Si}$ isomer(s) (108 amu) plus atomic hydrogen ( $\left.\mathrm{H} \cdot ; 1 \mathrm{amu}\right)$. The center-ofmass translational energy distribution, $\mathrm{P}\left(\mathrm{E}_{\mathrm{T}}\right)$, assists in the assignment of the product isomer(s). For those molecules formed without internal excitation, the high energy cutoff of the $\mathrm{P}\left(\mathrm{E}_{\mathrm{T}}\right)$ of 67 $\pm 7 \mathrm{~kJ} \mathrm{~mol}^{-1}$ represents the sum of the reaction exoergicity plus the collision energy. A subtraction of the collision energy suggests that the reaction is exoergic by $29 \pm 8 \mathrm{~kJ} \mathrm{~mol}^{-1}$. This value is in excellent agreement with the computed data $\left(-30 \pm 5 \mathrm{~kJ} \mathrm{~mol}^{-1}\right)$ to form the phenylsilane $\left(\mathrm{C}_{6} \mathrm{H}_{5} \mathrm{SiH}_{3}\right)$ isomer (Fig. 2). Further, the center-of-mass angular distribution, $T(\theta)$, shows intensity over the complete angular range from $0^{\circ}$ to $180^{\circ}$. The distribution exhibits 
pronounced intensity close to $180^{\circ}$, which is indicative of backward scattering. These findings suggest that at least one reaction channel follows rebound dynamics via a direct reaction involving a $\mathrm{C}_{6} \mathrm{H}_{5} \mathrm{SiH}_{4}$ transition state. Typically, this rebound pathway follows small impact parameters close to zero and should only exhibit intensity in the backward hemisphere. The finding that intensity was also observed at center-of-mass angles less than $90^{\circ}$ might be explained by trajectories with larger impact parameters leading to reaction and/or a channel involving a reaction intermediate (indirect scattering dynamics). It should be highlighted that a solely backward-scattered distribution could not fit the experimental data (Supplementary Figs. S3 and S4).

Having elucidated the synthesis of phenylsilane $\left(\mathrm{C}_{6} \mathrm{H}_{5} \mathrm{SiH}_{3}\right)$ as the product of the gas phase reaction of phenyl radicals with silane under single collision conditions, we now merge these findings with the computational results to untangle the underlying reaction mechanism(s) (Fig. 3a, Supplementary Information). These calculations predict the overall reaction energies and barriers to reaction to an accuracy of about $5 \mathrm{~kJ} \mathrm{~mol}^{-1}$. The reaction of the phenyl radical with silane can proceed via a classical, direct abstraction, [2b], forming benzene $\left(\mathrm{C}_{6} \mathrm{H}_{6}\right)$ plus the silyl radical $\left(\mathrm{SiH}_{3} \cdot\right)$ in an overall exoergic pathway $\left(-89 \mathrm{~kJ} \mathrm{~mol}^{-1}\right)$ via a transition state located $12 \mathrm{~kJ}$ mol $^{-1}$ above the separated reactants. In this $C_{s}$ symmetric transition state, the phenyl radical and silicon-hydrogen bond are nearly collinear $\left(177.4^{\circ}\right)$ with a carbon-hydrogen bond distance of $167.9 \mathrm{pm}$. The phenyl radical and the silane molecule can also approach without entrance barrier to form a weakly stabilized ( $\left.-5 \mathrm{~kJ} \mathrm{~mol}^{-1}\right)$ long-range van-der-Waals complex, in which the phenyl radical points with its radical center to the silicon atom of silane ( $\mathrm{C}_{\mathrm{s}}$ symmetry; carbon-silicon distance of $331.6 \mathrm{pm})$. This complex undergoes substitution, [2a], to form the detected phenylsilane $\left(\mathrm{C}_{6} \mathrm{H}_{5} \mathrm{SiH}_{3}\right)$ product plus atomic hydrogen in an overall exoergic reaction $(-30 \mathrm{~kJ}$ $\mathrm{mol}^{-1}$ ) via a transition state located $39 \mathrm{~kJ} \mathrm{~mol}^{-1}$ above the energy of the separated reactants. In this transition state, the silicon atom adopts a trigonal bipyramidal configuration with a carbonsilicon distance of $209.3 \mathrm{pm}$.

Let us now compare to the reaction of the phenyl radical with methane (Fig. 3b). In this carbon-based chemistry, two reaction pathways from a weakly stabilized van-der-Waals complex were characterized. The transition states leading to hydrogen abstraction [3b] and hydrogen replacement [3a] are 36 and $170 \mathrm{~kJ} \mathrm{~mol}^{-1}$ above the separated reactants. Remarkably, the energy 
of the transition state connected with the methyl substitution reaction to form phenylsilane $\left(\mathrm{C}_{6} \mathrm{H}_{5} \mathrm{SiH}_{3}\right)$ [2a] is reduced by $131 \mathrm{~kJ} \mathrm{~mol}^{-1}$ compared to the formation of toluene $\left(\mathrm{C}_{6} \mathrm{H}_{5} \mathrm{CH}_{3}\right)$ [3a] by replacing a carbon atom by isovalent silicon. This is because silicon has a much stronger tendency to form stable penta-coordinate transition states and intermediates relative to carbon, on account of stronger 3 center four electron interactions. ${ }^{10-11}$ Therefore, the barrier height difference between abstraction and substitution in the silane - phenyl system of only $27 \mathrm{~kJ} \mathrm{~mol}^{-1}$ makes the formation of phenylsilane $\left(\mathrm{C}_{6} \mathrm{H}_{5} \mathrm{SiH}_{3}\right)$ competitive compared to the synthesis of toluene $\left(\mathrm{C}_{6} \mathrm{H}_{5} \mathrm{CH}_{3}\right)$, where the difference of $144 \mathrm{~kJ} \mathrm{~mol}^{-1}$ effectively eliminates the substitution reaction [3a] compared to hydrogen abstraction [3b].

With the reaction to phenylsilane $\left(\mathrm{C}_{6} \mathrm{H}_{5} \mathrm{SiH}_{3}\right)$ proceeding via a radical substitution pathway, which is matched by the electrophilic nature of the phenyl radical and nucleophilic characteristics of the silane molecule, we proceed now to investigate quasi-classical trajectory (QCT) calculations for this reaction. ${ }^{12-14}$ This approach bridges the dynamics experiments with the theoretical understanding of the phenyl - silane system. With respect to the phenyl radical, both forward and backward scattering processes were explored at a collision energy of $38 \mathrm{~kJ}$ $\mathrm{mol}^{-1}$, as in the experiment. No substitution reactions leading to phenylsilane $\left(\mathrm{C}_{6} \mathrm{H}_{5} \mathrm{SiH}_{3}\right)$ plus atomic hydrogen were observed in 195 forward scattering trajectories, indicating that the stripping dynamics route was unlikely to be a major reactive pathway to form phenylsilane $\left(\mathrm{C}_{6} \mathrm{H}_{5} \mathrm{SiH}_{3}\right)$ plus atomic hydrogen [2a]. The atomic hydrogen abstraction processes [2b] were also exceedingly rare under those conditions, occurring in only a single trajectory. However, as verified experimentally based on the center-of-mass angular distribution (Fig. 2), a considerable number of reactive processes were observed for trajectories that displayed backward scattering leading to phenylsilane $\left(\mathrm{C}_{6} \mathrm{H}_{5} \mathrm{SiH}_{3}\right)$, suggesting that rebound dynamics are likely the principal route. This led us to specifically analyze head-on collisions between the phenyl radical $\left(\mathrm{C}_{6} \mathrm{H}_{5}{ }^{*}\right)$ and silane $\left(\mathrm{SiH}_{4}\right)$. The configurations explored have the silicon atom initially coplanar with the phenyl ring and closest to the carbon atom which carries the radical center. The initial fragment velocities are along the axis connecting the silicon atom with the radical center in order to ensure head-on collisions. Finally, one of the silane hydrogen atoms is constrained to be coplanar with the ring (in order to have a manageable number of degrees of freedom). This automatically allows us to define an angle $\theta_{\mathrm{HSiC}}$ between the initial axis of approach and the silicon-hydrogen $(\mathrm{Si}-\mathrm{H})$ bond and to explore behavior at different $\theta_{\mathrm{HSiC}}$. Figure $4 \mathrm{a}$ reveals that $\theta_{\mathrm{HSiC}}=0^{\circ}$ for 
instance, is ideal for the hydrogen abstraction channel [2b] as one of the hydrogen atoms is pointing straight towards the radical center; on the other hand, $\theta_{\mathrm{HSiC}}=180^{\circ}$ seems to be a good orientation for a bimolecular substitution reaction leading to phenylsilane $\left(\mathrm{C}_{6} \mathrm{H}_{5} \mathrm{SiH}_{3}\right)$ plus atomic hydrogen [2a] (Fig. 4b).

Figure 4c shows the probability of the occurrence of substitution [2a] and abstraction [2b] processes at a given $\theta_{\mathrm{HSiC}}$ as determined by averaging over 20 trajectories for each $\theta_{\mathrm{HSiC}}$, resulting in an overall analysis over 1400 trajectories. It is observed that the substitution process occurs over a wider range of angles covering two angular ranges from $25^{\circ}$ to $110^{\circ}$ and $135^{\circ}$ to $180^{\circ}$ compared to abstraction making the substitution reaction more likely than the abstraction processes. Quantitatively, $38 \pm 4 \%$ of the trajectories lead to substitution, while abstraction occurs in $12 \pm 3 \%$ of the cases, with the remaining $50 \pm 7$ trajectories being non-reactive. This leads to a branching ratio of $3.2 \pm 1$ for substitution over abstraction. Despite the disadvantage of the higher barrier to reaction (35 kJ mol${ }^{-1}$ versus $8 \mathrm{~kJ} \mathrm{~mol}^{-1}$ at the level of theory employed for QCT), the substitution pathway to phenylsilane $\left(\mathrm{C}_{6} \mathrm{H}_{5} \mathrm{SiH}_{3}\right)$ predominates, since it is less sensitive to orientation and adequate collision energy is supplied. The calculations therefore reveal a bias for the substitution pathway under head-on collision conditions at the average collision energy of $38 \mathrm{~kJ} \mathrm{~mol}^{-1}$, which is likely representative of a substantial number of reactive collisions. It is however important to note that this precise branching ratio is only applicable under those conditions, and it is possible that other unexplored pathways with different proportions of substitution to abstraction may exist.

The QCT calculations also provide a theoretically predicted center-of-mass angular distribution (Fig. 2), which matches qualitatively the experimentally derived center-of-mass angular distribution. Both distributions reveal a preferential backward-scattering of the heavy phenylsilane $\left(\mathrm{C}_{6} \mathrm{H}_{5} \mathrm{SiH}_{3}\right)$. Further, the occurrence of flux at angles lower than $140^{\circ}-180^{\circ}$ is evident. Incorporating the QCT-based center-of-mass angular distribution into the forward convolution routing to fit the laboratory data and adopting the velocity spreads of the phenyl and silane beams of about $10 \%$ reveals an exceptional fit of the laboratory data (Fig. 1; blue line); as evident from the forward convolution, mono energetic silane and phenyl beams result in simulated TOFs and a laboratory angular distribution which are too narrow compared to the experimental data (Fig. 1; green line). 
To conclude, our crossed molecular beam and quasi classical trajectory study of the phenyl silane system reveals the very first observation of a reaction mechanism leading via a single transition state, in which the silicon atom is penta-coordinated, to the formation of phenylsilane $\left(\mathrm{C}_{6} \mathrm{H}_{5} \mathrm{SiH}_{3}\right)$ and atomic hydrogen in the gas phase under single collision conditions. This marks the phenyl - silane system as a benchmark of a radical substitution mechanism involving carbonsilicon bond formation via a concerted, one step mechanism to unravel the chemical dynamics along with the differential cross sections of polyatomic systems incorporating a heavy silicon atom to eventually define our quantitative understanding of molecular structure, reactivity and dynamics of reaction mechanisms involving silicon. The facile formation of a silicon-carbon bond via a single collision event may also hold critical implications to the chemistry of extraterrestrial environments such as the carbon rich circumstellar envelope of the Asymptotic Giant Branch (AGB) Star IRC+10216. The recent detection of the silicon-bearing molecules cyanosilane $\left(\mathrm{SiH}_{3} \mathrm{CN}\right)^{15}$ and methylsilane $\left(\mathrm{CH}_{3} \mathrm{SiH}_{3}\right)^{16}$ might be rationalized via radical substitution reactions of the cyano $(\mathrm{CN} \cdot)$ and methyl $\left(\mathrm{CH}_{3} \cdot\right)$ radicals with silane $\left(\mathrm{SiH}_{4}\right)$ thus exploiting circumstellar environments not only as macroscopic, natural laboratories for extraordinary silicon-bearing molecules such as silicon dicarbide (SiCSi), ${ }^{17}$ but also for unusual reaction mechanisms on the microscopic, molecular level with barriers to reaction overcome easily in hot regions of the envelopes close to the central star holding temperatures of a few $1,000 \mathrm{~K}$. Note that Lunell et al. proposed a reaction mechanism of a homolytic substitution $\left(\mathrm{S}_{\mathrm{H}}\right)$ at $77 \mathrm{~K}$ in the condensed phase, where D3-methyl radicals $\left(\mathrm{CD}_{3} \cdot\right)$ were replaced by a methyl group $\left(\mathrm{CH}_{3}{ }^{\cdot}\right)$ in D3-methylsilane $\left(\mathrm{CH}_{3} \mathrm{SiD}_{3}\right) .{ }^{18}$ Under thermal conditions, this mechanism is problematic with electronic structure calculations revealing a transition state to reaction with a barrier height of $95 \mathrm{~kJ} \mathrm{~mol}^{-1}{ }^{19}$ which cannot be overcome at $77 \mathrm{~K}$. However, the methyl radical was generated via photolysis of methyl iodide $\left(\mathrm{CH}_{3} \mathrm{I}\right)$ that might lead to reaction via vibrationally excited methyl radicals. Later, Kulicke et al. proposed that in the liquid phase, silanes may undergo substitution reactions via carbon-silicon bond formation, which compete effectively with hydrogen abstraction. ${ }^{20}$ Condensed-phase kinetics ${ }^{18,20-21}$ and computational studies ${ }^{22-28}$ with silanes suggest that monosilane $\left(\mathrm{SiH}_{4}\right)$ is unreactive toward substitution reactions with alkyl radicals, however, that substitution reactions with disilane might be feasible, i.e. the reaction $\mathrm{H}+$ $\mathrm{Si}_{2} \mathrm{H}_{6} \rightarrow \mathrm{SiH}_{4}+\mathrm{SiH}_{3}$ is competitive with hydrogen abstraction ${ }^{18}$, 20-21; similar substitution reactions were also proposed for germanium-, tin-, and sulfur-centered molecules. ${ }^{18}$, 25,29 
However, although the radical products were identified by ESR, the reaction mechanism, i.e. concerted versus stepwise, was proposed only based upon electronic structure calculations of pertinent substitution transition states. Nevertheless, the elucidation of the underlying bimolecular reaction dynamics in the gas phase under single collision conditions in conjunction with elecronic strucutre and quasiclassical trajectory calculations as conducted in the present work provides for the very first time compelling evidence for the radical substitution mechanism via a penta-coordinated silicon atom.

\section{Methods}

Experimental Methods. The gas phase reaction of the phenyl radical $\left(\mathrm{C}_{6} \mathrm{H}_{5}\right)$ with silane $\left(\mathrm{SiH}_{4}\right)$ was studied under single collision conditions in a crossed molecular beams machine. ${ }^{30-33} \mathrm{~A}$ pulsed molecular beam of phenyl radicals was produced by photolyzing a $1 \%$ mixture of chlorobenzene (99.9 \%+, Sigma-Aldrich) seeded in helium (99.9999\%, Airgas) at a pressure of $1.8 \mathrm{~atm}$. This gas mixture is introduced into the primary source chamber by a piezoelectric pulse valve operating at $120 \mathrm{~Hz}$ and a pulse width of $80 \mu \mathrm{s}$; chlorobenzene is photolyzed by $193 \mathrm{~nm}$ radiation from an argon fluoride (ArF) excimer laser operating at $60 \mathrm{~Hz}$ and $32 \mathrm{~mJ} / \mathrm{pulse}$. The phenyl radical beam passes through a stainless steel skimmer, and a four-slot chopper wheel selects a well-defined peak velocity $\left(v_{\mathrm{p}}\right)$ and speed ratio (S) of $1636 \pm 17 \mathrm{~m} \mathrm{~s}^{-1}$ and $10.2 \pm 0.6$. This part of the radical beam is crossed perpendicularly with a pulsed silane beam (99.9997 \%; Linde) in the interaction region of the chamber. The pulsed silane beam is introduced through a second piezoelectric pulsed valve operating at $120 \mathrm{~Hz}$ and a pulse width of $80 \mu$ s with a backing pressure of 550 Torr. The peak velocity and speed ratio of silane were determined to $827 \pm 20 \mathrm{~m}$ $\mathrm{s}^{-1}$ and $10.1 \pm 0.2$ resulting in a collision energy $\left(E_{\mathrm{col}}\right)$ of $38.0 \pm 1.3 \mathrm{~kJ} \mathrm{~mol}^{-1}$ and a center-of-mass (CM) angle of $11.9 \pm 0.2^{\circ}$, respectively. The reactively scattered products were detected using a triply differentially pumped quadrupole mass spectrometer (QMS) operating in the time-of-flight (TOF) mode after electron-impact ionization of the neutral species with an electron energy of 80 $\mathrm{eV}$. Ions selected with a specific mass-to-charge ratio $(\mathrm{m} / \mathrm{z})$ were accelerated toward a stainless steel doorknob-shaped target coated with a thin layer of aluminum. The ions strike the surface and initiate an electron cascade. The electrons traveled towards an organic scintillator to create a photon pulse that is amplified by a photomultiplier tube (PMT). A discriminator used to filter the signal from the PMT before the TOF spectra is collected by a multichannel scaler. It should be 
stressed that in our setup, bimolecular collisions and hence reactions leading to phenylsilane only take place in the interaction region of the scattering chamber; they do not occur in the ionizer. The time-of-flight spectra were recorded over the full angular range of the reaction defined by the phenyl radical and silane molecular beams. The TOF spectra were integrated and normalized to obtain the product angular distribution in the laboratory frame (LAB) and the laboratory data was converted to the $\mathrm{CM}$ frame using a forward-convolution routine. This method initially chooses the product translational energy distribution $\left(P\left(E_{\mathrm{T}}\right)\right)$ and angular distribution $(T(\theta))$ in the CM frame to reproduce the TOF spectra and laboratory angular distribution.

Theoretical Methods. Geometry optimizations of various reactants, products, intermediates, and transition states involved in the $\mathrm{C}_{6} \mathrm{H}_{5}$ plus $\mathrm{SiH}_{4} / \mathrm{CH}_{4}$ reactions were carried out performed using the B2PLYP-D3 ${ }^{34-35}$ doubly hybrid density functional with the $6-311 \mathrm{G}^{* *}$ basis set. To characterize the nature of each stationary structure as a minimum or a saddle point, harmonic frequencies were calculated at the same B2PLYP-D3/6-311G** level. Zero-point vibrational energies (ZPE) for all structures were also obtained from the B2PLYP-D3/6-311G** calculations, and were accounted for in reaction energy and barrier calculations. The electronic energies for all chemical species, were calculated using explicitly correlated coupled cluster $\operatorname{CCSD}(\mathrm{T})-\mathrm{F} 12^{36-37}$ calculations with the cc-pVTZ-F12 basis set, ${ }^{38-39}$ which are expected to closely approach the complete basis set (CBS) limit and to be accurate within $5 \mathrm{~kJ} \mathrm{~mol}^{-1}$. The calculations were carried out using the GAUSSIAN $09^{40}$ and MOLPRO $2010^{41}$ program packages.

QCT trajectories were run in a development version of the Q-Chem 4.0 package at the $\omega \mathrm{B} 97 \mathrm{X}-$ $\mathrm{V} / 6-31+\mathrm{G}^{*}$ level of theory. ${ }^{42-48}$ The local xc integrals were integrated over a radial grid of 75 points and an angular Lebedev grid of 302 points, while the non-local VV10 correlation was integrated over an SG-1 grid. ${ }^{49}$ This level of theory was found to reproduce the more expensive wavefunction theory stationary point relative energies described above to $5 \mathrm{~kJ} \mathrm{~mol}^{-1}$. The time step for the AIMD simulations was $1.21 \mathrm{fs}$ ( 50 a.u.) and the total simulation time was $0.484 \mathrm{ps}$ (400 time steps). Further details regarding the QCT calculations are provided in the Supporting Information.

Acknowledgments: The Hawaii group thanks the National Science Foundation (NSF) for support under award CHE-1360658. Work at Berkeley was supported by the Director, Office of 
Science, Office of Basic Energy Sciences, of the U.S. Department of Energy under Contract No. DE- AC02-05CH11231. D.H. also acknowledges funding via a Berkeley Fellowship.
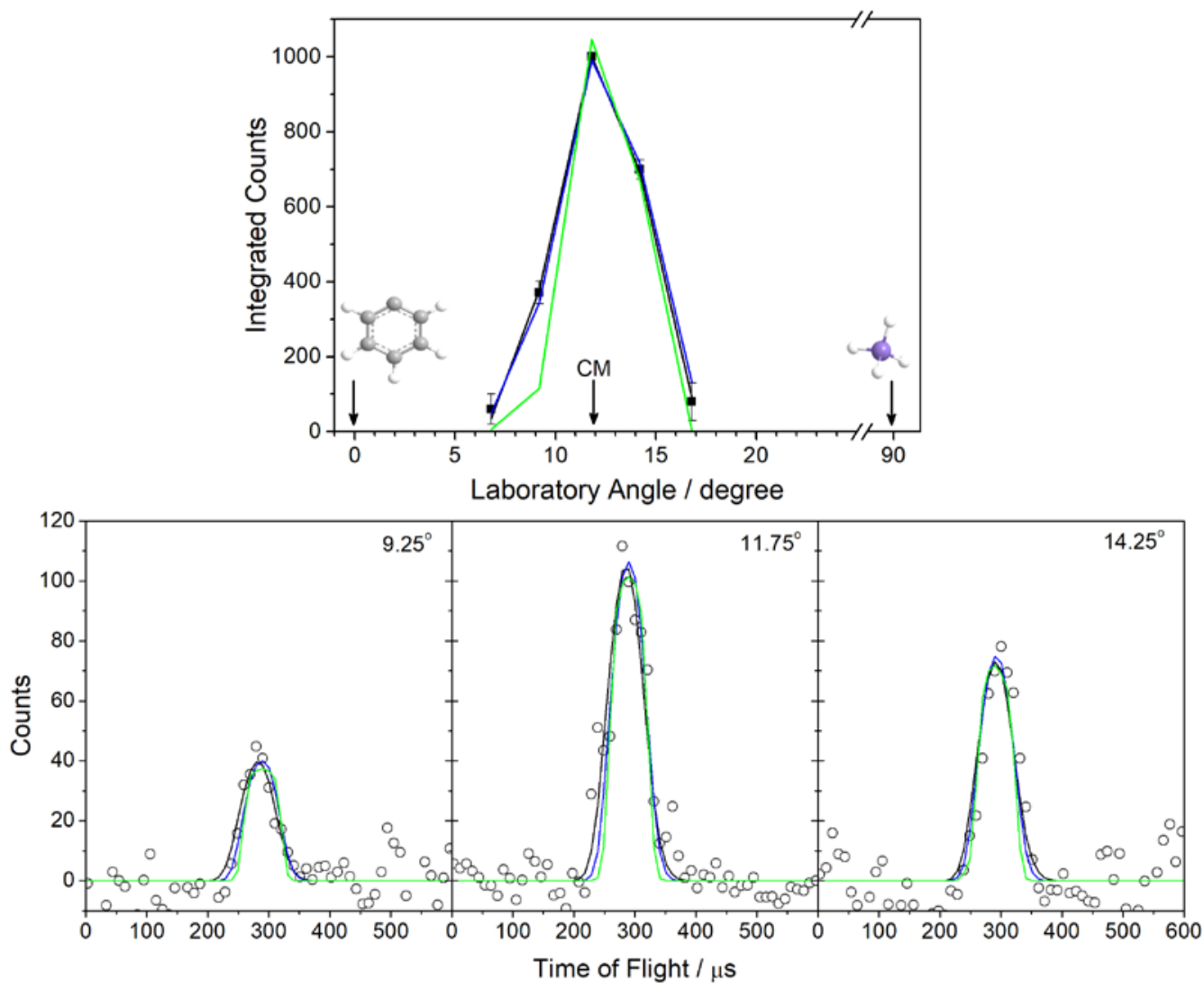

Fig. 1. Laboratory angular distribution (top) and time-of-flight (TOF) spectra (bottom) recorded at a mass-to-charge $(\mathrm{m} / \mathrm{z})$ of 105 for the reaction of phenyl $\left(\mathrm{C}_{6} \mathrm{H}_{5}\right)$ and silane $\left(\mathrm{SiH}_{4}\right)$. The solid squares represent the integrated counts for the recorded angle. The open circles represent the experiment TOF spectra. The solid line represent the best fits obtained from the forwardconvolution routine. The fits in blue and green result from the QCT-based center-of-mass angular distribution with velocity spreads of the phenyl and silane beams of about $10 \%$ (blue) and mono energetic beams (green). 

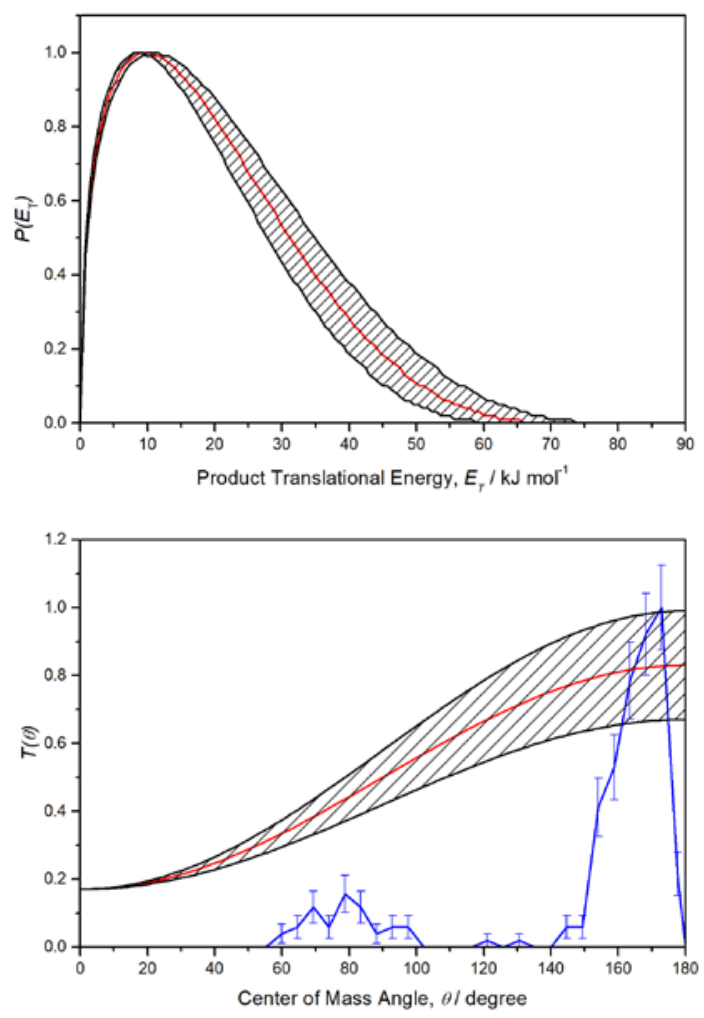

Fig. 2. Center-of-mass translational energy distribution $P\left(E_{\mathrm{T}}\right)$ (top) and angular distribution $T(\theta)$ (bottom) for the formation of phenylsilane $\left(\mathrm{C}_{6} \mathrm{H}_{5} \mathrm{SiH}_{3}\right)$ plus atomic hydrogen via the reaction of the phenyl radical and silane. The shaded areas show the experimental error limits. QCT calculations provide the center-of-mass angular distribution color coded in blue. The differences between the experimental and QCT center-of-mass angular distributions arise from the latter being exclusively based on head-on collisions with zero impact parameter, while alternative approaches are possible under the experimental conditions. The qualitative agreement between experiments and theory is consistent with the proposal that backward scattering is the major reactive pathway. 
(a)

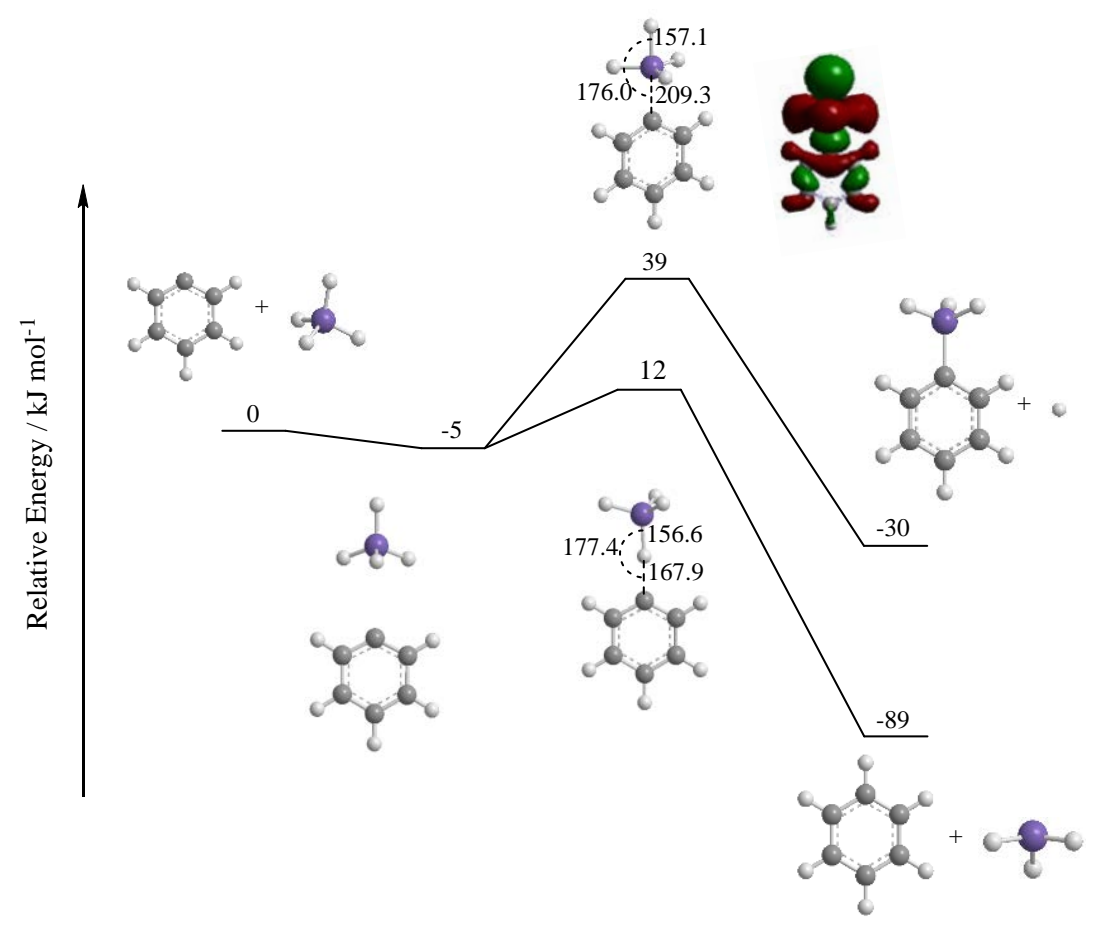

(b)

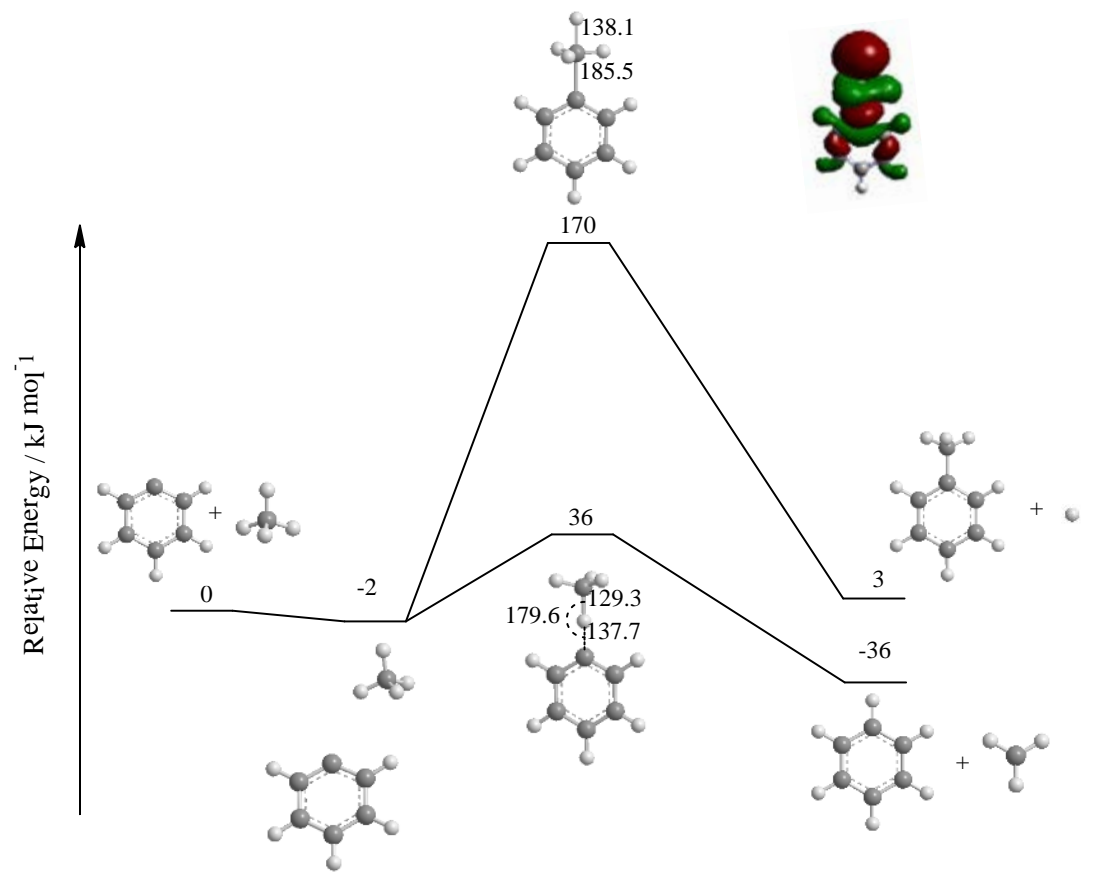

Fig. 3. Potential energy surfaces (PESs) in $\mathrm{kJ} \mathrm{mol}^{-1}$ for the reactions of the phenyl radical with silane (a) and methane (b), respectively. Bond lengths and bond angles are given in pm and degrees, respectively. The highest occupied molecular orbital (HOMO) of the substitution transition states are also shown. Structures along with the vibrational frequencies of the reactants, intermediates, products, and transition states are compiled in the Supplementary Material (Table S1). 
(a)
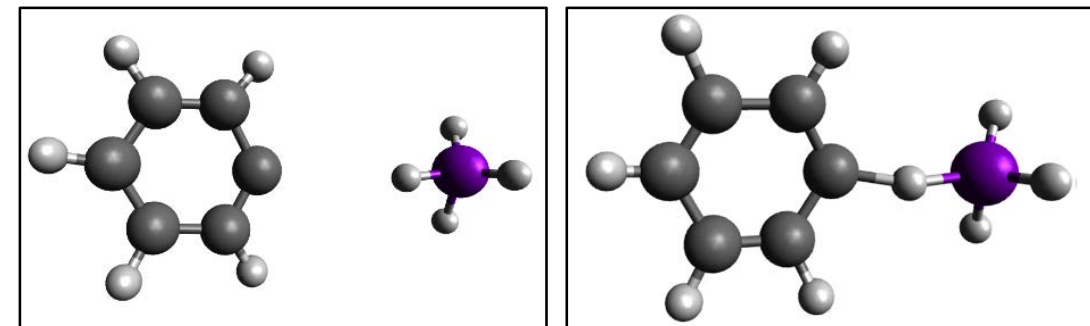

(b)
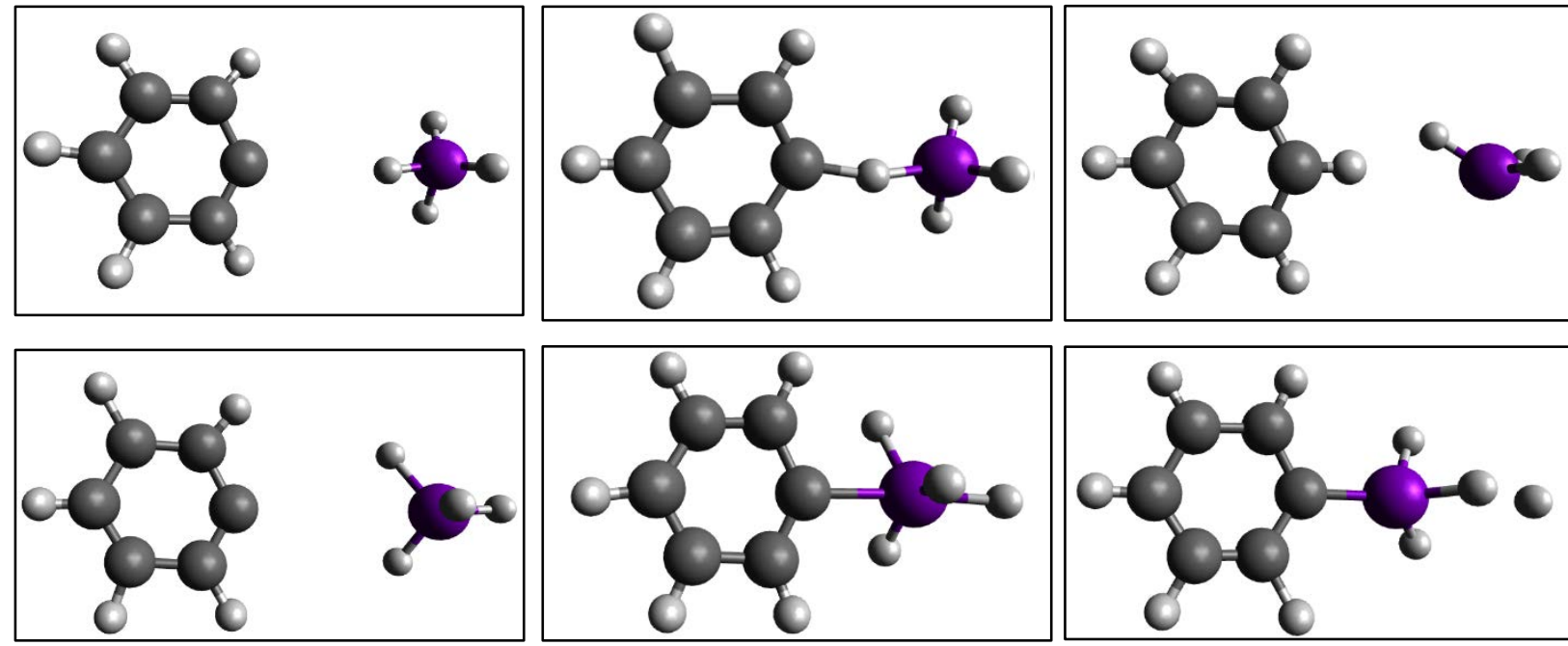

(c)

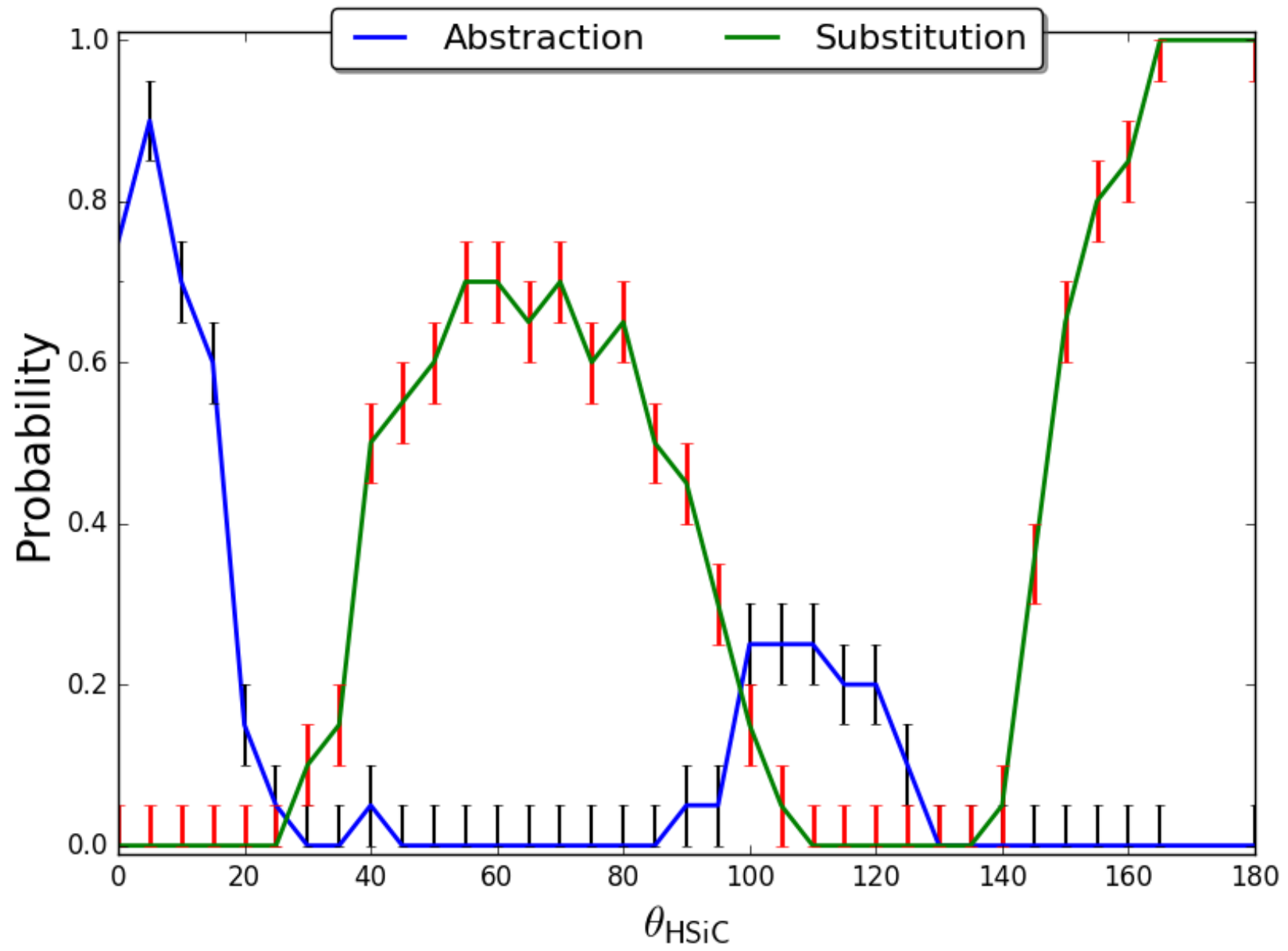


Figure 4. (a) Trajectories leading to abstraction with an initial angle $\theta_{\mathrm{HSiC}}=0^{\circ}$ on the left, which leads to a collision that accesses the transition structure in the center where the $\mathrm{H}$ atom is shared between the silane and the phenyl, before it is completely abstracted by the latter leaving behind a silyl radical as shown in the right. (b) Trajectories leading to substitution with an initial angle $\theta_{\mathrm{HSiC}}=180^{\circ}$ on the left, which results in a collision that accesses the pentavalent silicon transition structure in the center that subsequently ejects a hydrogen atom to complete the $\mathrm{S}_{\mathrm{R}} 2$ substitution reaction producing phenylsilane as shown in the right. (c) Probability of the substitution and abstraction processes occurring at a given angle $\theta_{\mathrm{HSiC}}$, determined from averaging over 20 trajectories for each angle. The least count is thus one trajectory leading to an uncertainty of 0.05 . This mechanism predicts configuration inversion at the silicon atom, if the Si atom has three different non-hydrogen substituents. The movies of the corresponding trajectories can be accessed in the Supplementary Information.

\section{Supplementary Material}

Supplementary Text

Comparison between calculated barrier height and experimental collision energy

Note on QCT calculations

Figures S1-S4

Tables S1-S4

Movies S1-S2 


\section{References:}

1. Cowdrey, W. A.; Hughes, E. D.; Ingold, C. K.; Masterman, S.; Scott, A. D., Reaction Kinetics and the Walden Inversion. VI. Relation of Steric Orientation to Mechanism in Substitutions Involving Halogen Atoms and Simple or Substituted Hydroxyl Groups. J. Chem. Soc. 1937, 1252-1271.

2. Kharasch, M. S.; Mayo, F. R., Peroxide Effect in the Addition of Reagents to Unsaturated Compounds. I. The Addition of Hydrogen Bromide to Allyl Bromide. J. Am. Chem. Soc. 1933, 55, 2468-2490.

3. Wheland, G. W., A Quantum-Mechanical Investigation of the Orientation of Substituents in Aromatic Molecules. J. Am. Chem. Soc. 1942, 64, 900-908.

4. Ingold, C. K., Structure and Mechanism in Organic Chemistry. 2nd ed.; Cornell Univ. Press: 1969.

5. $\quad$ Crampton, M. R., Nucleophilic Aromatic Substitution. Org. React. Mech. 2011, 233-256.

6. Taylor, R., Electrophilic Aromatic Substitution. Wiley: 1990.

7. Camden, J. P.; Bechtel, H. A.; Zare, R. N., Dynamics of the Simplest Reaction of a Carbon Atom in a Tetrahedral Environment. Angew. Chem., Int. Ed. 2003, 42, 5227-5230.

8. Germann, G. J.; Huh, Y. D.; Valentini, J. J., State-to-State Dynamics of Atom + Polyatom Abstraction Reactions. I. The $\mathrm{H}+\mathrm{CD}_{4} \rightarrow \mathrm{HD}\left(\mathrm{v}^{\prime}, \mathrm{J}^{\prime}\right)+\mathrm{CD}_{3}$ Reaction. J. Chem. Phys. 1992, 96, 1957-1966.

9. Chattopadhyay, A.; Tasaki, S.; Bersohn, R.; Kawasaki, M., The Inversion Mechanism for the Reaction $\mathrm{H}+\mathrm{CD}_{4} \rightarrow \mathrm{CD}_{3} \mathrm{H}+$ D. J. Chem. Phys. 1991, 95, 1033-1036.

10. Sini, G.; Ohanessian, G.; Hiberty, P. C.; Shaik, S. S., Why is $\mathrm{SiH}_{5}{ }^{-}$a Stable Intermediate While $\mathrm{CH}_{5}{ }^{-}$is a Transition State? A Quantitative Curve Crossing Valence Bond Study. J. Am. Chem. Soc. 1990, 112, 1407-1413.

11. Albright, T. A.; Burdett, J. K.; Whangbo, M.-H., Orbital Interactions in Chemistry. John Wiley \& Sons: 2013.

12. Karplus, M.; Porter, R. N.; Sharma, R. D., Exchange Reactions with Activation Energy. I. Simple Barrier Potential for $\left(\mathrm{H}_{2} \mathrm{H}_{2}\right)$. J. Chem. Phys. 1965, 43, 3259-3287.

13. Porter, R. N., Molecular Trajectory Calculations. Annu. Rev. Phys. Chem. 1974, 25, 317355.

14. Porter, R. N.; Raff, L. M.; Miller, W. H., Quasiclassical Selection of Initial Coordinates and Momenta for a Rotating Morse Oscillator. J. Chem. Phys. 1975, 63, 2214-2218.

15. Agundez, M.; Cernicharo, J.; Guelin, M., New Molecules in IRC +10216: Confirmation of $\mathrm{C}_{5} \mathrm{~S}$ and Tentative Identification of $\mathrm{MgCCH}, \mathrm{NCCP}$, and $\mathrm{SiH}_{3} \mathrm{CN}$. Astron. Astrophys. 2014, 570, A45.

16. Cernicharo, J.; Agundez, M.; Velilla, P. L.; Pardo, J. R.; Quintana-Lacaci, G.; Fonfria, J. P.; Marcelino, N.; Tercero, B.; Moreno, E.; Massalkhi, S., et al., Discovery of Methyl Silane and Confirmation of Silyl Cyanide in IRC +10216. Astron Astrophys 2017, 606, L5.

17. Cernicharo, J.; McCarthy, M. C.; Gottlieb, C. A.; Agundez, M.; Prieto, L. V.; Baraban, J. H.; Changala, P. B.; Guelin, M.; Kahane, C.; Martin- Drumel, M. A., et al., Discovery of SiCSi in IRC+10216: A Missing Link between Gas and Dust Carriers of Si-C Bonds. Astrophys. J., Lett. 2015, 806, 1-6.

18. Komaguchi, K.; Norberg, D.; Nakazawa, N.; Shiotani, M.; Persson, P.; Lunell, S., Direct ESR Evidence for $\mathrm{S}_{\mathrm{H}} 2$ Type Reaction of Methyl Radical with Methylsilane and Methylgermane in a Low Temperature Solid: A Deuterium Labeling Study. Chem. Phys. Lett. 2005, 410, 1-5. 
19. Sillars, D. S.; Bennett, C. J.; Osamura, Y.; Kaiser, R. I., Infrared Spectroscopic Detection of the Methylsilyl $\left(\mathrm{CH}_{3} \mathrm{SiH}_{2}, \mathrm{X}^{2} \mathrm{~A}^{\prime}\right)$ and the Silylmethyl $\left(\mathrm{CH}_{2} \mathrm{SiH}_{3}, \mathrm{X}^{2} \mathrm{~A}^{\prime}\right)$ Radicals and Their Partially Deuterated Counterparts in Low Temperature Matrices. Chem. Phys. 2005, 315, 41-52.

20. Kulicke, K. J.; Chatgilialoglu, C.; Kopping, B.; Giese, B., Homolytic Substitution Reaction at a Silicon Atom. Helv. Chim. Acta 1992, 75, 935-939.

21. Fabry, L.; Potzinger, P.; Reimann, B.; Ritter, A.; Steenbergen, H. P., Gas-Phase Homolytic Substitution Reactions of Hydrogen Atoms at Silicon Centers. Organometallics 1986, 5, 1231-1235.

22. Horvat, S. M.; Schiesser, C. H., Ab Initio and DFT Study of Homolytic Substitution Reactions of Acyl Radicals at Silicon, Germanium, and Tin. Organometallics 2009, 28, 33113318.

23. Schiesser, C. H.; Styles, M. L.; Wild, L. M., Ab Initio Study of Some Free-Radical Homolytic Substitution Reactions at Silicon, Germanium and Tin. J. Chem. Soc., Perkin Trans. 2 1996, 2257-2262.

24. Norberg, D.; Shiotani, M.; Lunell, S., $\mathrm{S}_{\mathrm{H}} 2$ Reaction Versus Hydrogen Abstraction/Expulsion in Methyl Radical-Methylsilane Reactions: Effects of Prereactive Complex Formation. J. Phys. Chem. A 2008, 112, 1330-1338.

25. Tanko, J. M., Reaction Mechanisms. Part I: Radical and Radical Ion Reactions. Annu. Rep. Prog. Chem., Sect. B 2010, 106, 260-282.

26. Matsubara, H.; Horvat, S. M.; Schiesser, C. H., Methyl Radical Also Reacts by the Frontside Mechanism: An Ab Initio Study of Some Homolytic Substitution Reactions of Methyl Radical at Silicon, Germanium and Tin. Org. Biomol. Chem. 2003, 1, 1199-1203.

27. Matsubara, H.; Schiesser, C. H., An Ab-Initio Study of Some Homolytic Substitution Reactions of Acyl Radicals at Silicon, Germanium and Tin. Org. Biomol. Chem. 2003, 1, 43354341.

28. Horvat, S. M.; Schiesser, C. H.; Wild, L. M., Free Radical Homolytic Substitution by the Frontside Mechanism: Ab Initio Study of Homolytic Substitution Reactions at Silicon, Germanium, and Tin. Organometallics 2000, 19, 11239-11246.

29. Wisniowski, P.; Bobrowski, K.; Carmichael, I.; Hug, G. L., Bimolecular Homolytic Substitution $\left(\mathrm{S}_{\mathrm{H}} 2\right)$ Reactions with Hydrogen Atoms. Time-Resolved Electron Spin Resonance Detection in the Pulse Radiolysis of $\alpha$-(Methylthio)acetamide. J. Am. Chem. Soc. 2004, 126, 14468-14474.

30. Gu, X.; Guo, Y.; Zhang, F.; Mebel, A. M.; Kaiser, R. I., Reaction Dynamics of CarbonBearing Radicals in Circumstellar Envelopes of Carbon Stars. Faraday Discuss. 2006, 133, 245275.

31. Gu, X.; Kaiser, R. I., Reaction Dynamics of Phenyl Radicals in Extreme Environments: A Crossed Molecular Beam Study. Acc. Chem. Res. 2009, 42, 290-302.

32. Guo, Y.; Gu, X.; Kawamura, E.; Kaiser, R. I., Design of a Modular and Versatile Interlock System for Ultrahigh Vacuum Machines: A Crossed Molecular Beam Setup as a Case Study. Rev. Sci. Instrum. 2006, 77, 034701.

33. Kaiser, R. I.; Maksyutenko, P.; Ennis, C.; Zhang, F.; Gu, X.; Krishtal, S. P.; Mebel, A. M.; Kostko, O.; Ahmed, M., Untangling the Chemical Evolution of Titan's Atmosphere and Surface-From Homogeneous to Heterogeneous Chemistry. Faraday Discuss. 2010, 147, 429478.

34. Grimme, S., Semiempirical Hybrid Density Functional with Perturbative Second-Order Correlation. J. Chem. Phys. 2006, 124, 034108. 
35. Grimme, S.; Ehrlich, S.; Goerigk, L., Effect of the Damping Function in Dispersion Corrected Density Functional Theory. J. Comput. Chem. 2011, 32, 1456-1465.

36. Purvis, G. D., III; Bartlett, R. J., A Full Coupled-Cluster Singles and Doubles Model: The Inclusion of Disconnected Triples. J. Chem. Phys. 1982, 76, 1910-1918.

37. Knizia, G.; Adler, T. B.; Werner, H.-J., Simplified CCSD(T)-F12 Methods: Theory and Benchmarks. J. Chem. Phys. 2009, 130, 054104.

38. Dunning, T. H., Jr., Gaussian Basis Sets for Use in Correlated Molecular Calculations. I. The Atoms Boron Through Neon and Hydrogen. J. Chem. Phys. 1989, 90, 1007-1023.

39. Peterson, K. A.; Adler, T. B.; Werner, H.-J., Systematically Convergent Basis Sets for Explicitly Correlated Wavefunctions: The Atoms H, He, B-Ne, and Al-Ar. J. Chem. Phys. 2008, 128, 084102.

40. Frisch, M. J.; Trucks, G. W.; Schlegel, H. B.; Scuseria, G. E.; Robb, M. A.; Cheeseman, J. R.; Scalmani, G.; Barone, V.; Mennucci, B.; Petersson, G. A., et al. Gaussian 09, Revision B.01, Gaussian Inc.: Wallingford CT, 2009.

41. Werner, H.-J.; Knowles, P. J.; Knizia, G.; Manby, F. R.; Schütz, M.; Celani, P.; Györffy, W.; Kats, D.; Korona, T.; Lindh, R., et al. MOLPRO, version 2010.1, a package of ab initio programs, see http://www.molpro.net.

42. Shao, Y.; Gan, Z.; Epifanovsky, E.; Gilbert, A. T. B.; Wormit, M.; Kussmann, J.; Lange, A. W.; Behn, A.; Deng, J.; Feng, X., et al., Advances in Molecular Quantum Chemistry Contained in the Q-Chem 4 Program Package. Mol. Phys. 2015, 113, 184-215.

43. Mardirossian, N.; Head-Gordon, M., $\omega B$ 97X-V: A 10-Parameter, Range-Separated Hybrid, Generalized Gradient Approximation Density Functional with Nonlocal Correlation, Designed by a Survival-of-the-Fittest Strategy. Phys. Chem. Chem. Phys. 2014, 16, 9904-9924.

44. Hariharan, P. C.; Pople, J. A., Influence of Polarization Functions on MO Hydrogenation Energies. Theor. Chim. Acta 1973, 28, 213-222.

45. Francl, M. M.; Pietro, W. J.; Hehre, W. J.; Binkley, J. S.; Gordon, M. S.; DeFrees, D. J.; Pople, J. A., Self-Consistent Molecular Orbital Methods. XXIII. A Polarization-Type Basis Set for Second-Row Elements. J. Chem. Phys. 1982, 77, 3654-3665.

46. Clark, T.; Chandrasekhar, J.; Spitznagel, G. W.; Schleyer, P. v. R., Efficient Diffuse Function-Augmented Basis Sets for Anion Calculations. III. The 3-21+G Basis Set for First-Row Elements, Li-F. J. Comput. Chem. 1983, 4, 294-301.

47. Krishnan, R.; Binkley, J. S.; Seeger, R.; Pople, J. A., Self-Consistent Molecular Orbital Methods. XX. A Basis Set for Correlated Wave Functions. J. Chem. Phys. 1980, 72, 650-654.

48. Gill, P. M. W.; Johnson, B. G.; Pople, J. A.; Frisch, M. J., The Performance of the BeckeLee-Yang-Parr (B-LYP) Density-Functional Theory with Various Basis Sets. Chem. Phys. Lett. 1992, 197, 499-505.

49. Gill, P. M. W.; Johnson, B. G.; Pople, J. A., A Standard Grid for Density Functional Calculations. Chem. Phys. Lett. 1993, 209, 506-512. 